\title{
A study on damage to PLA knitted fabrics during scouring and bleaching
}

\author{
Gulzar A. Baig ${ }^{1 *}$, Chris M. Carr ${ }^{2}$ \\ ${ }^{1}$ University of Manchester, Department of Textiles \& Paper, School of Materials, Manchester M60 1QD, UK \\ ${ }^{2}$ The University of Leeds, The School of Art \& Design, UK \\ "Corresponding author: e-mail: gabaig@bzu.edu.pk
}

\begin{abstract}
Ingeo ${ }^{\circledast}$ PLA (polylactic acid) knitted fabric was scoured through an exhaust technique. The scouring was carried out with sodium carbonate in the presence of a detergent at various concentrations and temperatures. The scoured fabric was bleached with various oxidative bleaching agents. Bleaching was carried out with hydrogen peroxide, sodium chlorite and sodium hypochlorite. Hydrogen peroxide was applied by exhaust and cold pad batch (CPB) techniques. It was observed that during scouring PLA fabric was degraded at high alkali concentrations and processing temperatures. The scouring temperature above $60^{\circ} \mathrm{C}$ proved to be deleterious due to the scouring solution penetrating into the polymer structure and damaged the fiber. Sodium chlorite and sodium hypochlorite caused little damage to the mechanical properties of PLA. Hydrogen peroxide when applied by the CPB technique did not reduce strength appreciably but when applied by the exhaust technique decreased the strength significantly. SEM analysis revealed that hydrogen peroxide caused holes and slit formation in the fiber structure.
\end{abstract}

Keywords: PLA, Scouring, Bleaching, Weight loss, Mechanical properties, SEM.

\section{INTRODUCTION}

PLA (Polylactic acid) is a new renewable and biodegradable material. Biodegradable materials are broken down into simpler and stable molecules, through macromolecular chain scission, in the presence of aerobic or anaerobic microorganisms ${ }^{1,2}$. PLA is a synthetic thermoplastic material derived from natural resources ${ }^{3}$. From the chemistry viewpoint, PLA is a polyester manufactured from the condensation polymerization of lactic acid, the latter being produced by the enzymatic action on $\operatorname{corn}^{3}$. Cargill Dow LCC, established in 1997, is the largest manufacturer of PLA fibres marketed under the trade name of Ingeo ${ }^{\circledR 4}$. Like PET (polyethylene terephthalate), PLA does not depend on petrochemical resources. PLA has some characteristics which are comparable to PET $^{5}$. These characteristics include the moisture regain, tensile strength, and crease resistance behaviour. PLA has some characteristics which are superior to PET. These include the specific gravity (PET 1.39, PLA 1.25) which make PLA a lightweight material, UV resistance (PET fair, PLA excellent) and refractive index (PET 1.54, PLA 1.4 $)^{6}$. At the same dye concentrations, the deeper shade on PLA as compared to PET has been explained to be due to higher refractive index of the former ${ }^{6}$. The drawbacks of PLA are its poor thermal and hydrolytic stability. PLA has low glass transition $\left(\mathrm{T}_{\mathrm{g}} 55-65^{\circ} \mathrm{C}\right)$ and melting temperatures $\left(T_{m} 130-175^{\circ} \mathrm{C}\right)^{3,7}$. Therefore, PLA should not be treated at the harsh and severe process conditions as are employed for industry standard polyester i.e. PET and blends of PET with natural fibres. The wet processing of PLA, therefore, requires a new process design that ensures retention of good overall mechanical, aesthetic and performance properties at the end of wet processing.

Textile fibres have various types of natural and added impurities which impart them creamy colour ${ }^{8-10}$. These impurities include the sizing chemicals, lubricants and waxes, anti-static agents, dirt and dust particles etc ${ }^{\mathbf{1 1}}$. Pre-treatments include a series of processes aimed at removing these impurities which otherwise may pose problems during dyeing and finishing ${ }^{12}$. Scouring and bleaching are the two important pre-treatment processes considered in this work. On industrial scale scouring is carried out in the presence of detergents and alkalies at different temperatures that may range from $60^{\circ} \mathrm{C}$ to $100^{\circ} \mathrm{C}$. Generally, synthetic fibres do not contain coloured impurities as do most of the natural fibres and hence do not require bleaching. However, in some cases where extra whiteness is required or where synthetic fibres are mixed with natural fibres, the former have to bear the severe chemical conditions required to bleach the later ${ }^{13}$.

There is a little literature related to the degradation of PLA particularly during pretreatment processes. Joziasse et al. ${ }^{14}$ studied the hydrolysis of PLA and reported that hydrolysis was autocatalytic due to the production of carboxylic groups at the polymer chain ends ${ }^{14}$. Grizzi et al. ${ }^{15}$ and Nakamura et al. ${ }^{16}$ studied hydrolysis of PLA at $\mathrm{pH} 7.4$ and temperature $37^{\circ} \mathrm{C}$ and reported that bulk hydrolysis was faster than the surface due to the accumulation of oligomers inside PLA material ${ }^{15,}{ }^{16}$. Baig studied the effect of various simulated textile processes such as scouring, bleaching, dyeing and reduction clearing on the hydrolytic stability of PLA fabric and concluded that weight and tensile properties decreased rapidly above $\mathrm{T}_{\mathrm{g}}$ of $\mathrm{PLA}^{17,18}$. Baig et al. ${ }^{19}$ investigated the effect of scouring and bleaching on the hydrolytic stability of PLA knitted fabric and concluded that hydrogen peroxide was deleterious to the integrity of PLA ${ }^{19}$. Ahmed studied the hydrolytic stability of PLA during various simulated textile processes and concluded that degradation depended on processing temperature, treatment time and $\mathrm{pH}$ of the medium. The high temperature, long process times and neutral to alkaline $\mathrm{pH}$ medium caused excessive loss in mechanical properties of PLA yarns. The result showed that acidic $\mathrm{pH}$ in the range of 4.5-5.0 was the most suitable one for the integrity of PLA material ${ }^{20}$. Suesat et al. studied the pretreatment and dyeing of PLA/cotton blended fabric and found that bleaching process for cotton severely damaged PLA ${ }^{21}$.

The present work was undertaken mainly to study the effect of pre-treatments on the tensile properties of PLA yarn. The scouring was carried out at various temperature and alkali concentrations through an exhaust technique. Bleaching was carried out with various 
industrially important bleaching agents such as hydrogen peroxide, sodium chlorite and sodium hypochlorite. The bleaching agents were applied at various concentrations while $\mathrm{pH}$ and temperature values were adopted that were mostly employed for the bleaching of cotton fabrics so that the stability of PLA to these process conditions was evaluated. The electron microscopic analysis was carried out to study the effects of various scouring and bleaching process conditions on the morphology of fibres. Hydrolytic stability of PLA was of the main concern in this work as most of the exhaust textile processes were carried out in aqueous medium. The process conditions where PLA yarn was most stable were identified so that textiles with good tensile properties were obtained.

\section{EXPERIMENTAL}

\section{Material and methods}

Mathis Labomat IR (infra red) dyeing machine (BFA 12, UK) was used to pretreat the PLA fabric. Henna $\mathrm{PH}-201$ digital $\mathrm{pH}$ meter was used to measure $\mathrm{pH}$ of the pretreatment bath before and after pretreatments. Knitted fabric constructed from $100 \%$ Ingeo $^{\circledR}$ spun yarn $\left(30^{\mathrm{s}} \mathrm{Ne}\right)$ was used throughout the experimental work. Sodium hydroxide, sodium carbonate, acetic acid, sodium dihydrogen phosphate, sodium bisulphite and formic acid were of laboratory grade.

\section{Scouring of PLA}

Greige knitted PLA fabric was scoured in IR dyeing machine. Alkali and processing temperature were the parameters studied. Sodium carbonate concentration was varied from $0.5-5 \mathrm{~g} / \mathrm{l}$ and temperature studied were $40,60,80$ and $100^{\circ} \mathrm{C}$. Kieralon Jet B conc. (fatty methyl ester ethoxylate, BASF) was used at a concentration of $0.5 \mathrm{~g} / \mathrm{l}$ in all the treatments. Scouring was carried out for 20 minutes at liquor to material ratio (LMR) of 10:1. After scouring the fabric was rinsed with cold water followed by neutralization with acetic acid. A final rinse was given with cold water and the fabric subsequently dried at ambient conditions. The process profile is shown in Figure 1.

\section{Bleaching of PLA}

1. Hydrogen peroxide $\left(\mathrm{H}_{2} \mathrm{O}_{2}\right)$ bleaching: The scoured PLA fabric (sodium carbonate $1 \mathrm{~g} / \mathrm{l}, 60^{\circ} \mathrm{C}, 20$ minutes \& LMR 20:1) was subjected to intense bleaching conditions which might be used for cotton to have full bleach effect. The fabric was treated with $1,2,3$ and $5 \mathrm{ml} / 1$ hydrogen peroxide $(35 \% \mathrm{w} / \mathrm{w}), \mathrm{x} \mathrm{ml} / \mathrm{l}$ sodium hydroxide $\left(50 \% \mathrm{w} / \mathrm{w}\right.$ ) and $0.5 \mathrm{gm} / \mathrm{l}$ Baystabil DB (organic $\mathrm{H}_{2} \mathrm{O}_{2}$ stabilizer; BASF) at $90^{\circ} \mathrm{C}$ for 45 minutes. The fabric was then rinsed with hot water $\left(60^{\circ} \mathrm{C}\right)$ for 15 minutes followed by neutralization with acetic acid and then dried at ambient conditions. The process file is shown in Figure 1. In the cold pad batch (CPB), PLA scoured fabric was padded with solutions containing 10, 20, 30 and $50 \mathrm{ml} / \mathrm{l}$ hydrogen peroxide $(35 \% \mathrm{w} / \mathrm{w}), 20 \mathrm{ml} / \mathrm{l}$ sodium hydroxide $(50 \% \mathrm{w} / \mathrm{w}), 1 \mathrm{~g} / 1$ Kieralon Jet B. conc. and 10 $\mathrm{g} / \mathrm{l}$ Baystabil DB at $20^{\circ} \mathrm{C}$ and $100 \%$ pick up. The fabric was wrapped in polyethylene sheet and left for a dwell time of $24 \mathrm{hrs}$. The fabric was subsequently washed with hot water $\left(60^{\circ} \mathrm{C}\right)$ for 15 minutes, rinsed with cold water, neutralized with acetic acid and finally dried at ambient conditions.

2. Sodium chlorite bleaching: The scoured PLA fabric (sodium carbonate $1 \mathrm{~g} / \mathrm{l}, 60^{\circ} \mathrm{C}, 20$ minutes \& LMR 20:1) was treated in a bath containing 2, 4, 6 and $10 \%$ on the weight of fabric (o.w.f) sodium chlorite (80\%), $3 \mathrm{~g} / \mathrm{l}$ sodium nitrate, $4 \mathrm{~g} / \mathrm{l}$ sodium di-hydrogen phosphate and $0.5 \mathrm{~g} / \mathrm{l}$ Kieralon Jet $\mathrm{B}$ conc. The $\mathrm{pH}$ of the liquor was adjusted to $\sim 4$ with formic acid. The bleaching was carried out at $85^{\circ} \mathrm{C}$ for 45 minutes followed by washing $\left(60^{\circ} \mathrm{C}\right)$ for 15 minutes and rinsing with cold water. The fabric was dried at ambient conditions. The process file is shown in Figure 1.

3. Sodium hypochlorite bleaching:

The scoured PLA fabric (sodium carbonate $1 \mathrm{~g} / \mathrm{l}$, $60^{\circ} \mathrm{C}, 20$ minutes \& LMR 20:1) was treated in a bath containing 2, 4, 6 and $10 \mathrm{~g} / \mathrm{l}$ available chlorine (sodium hypochlorite, $14 \% \mathrm{w} / \mathrm{w}$ ), the $\mathrm{pH}$ being adjusted to 11 $\sim 11.5$ with sodium carbonate. The treatment was carried out at $40^{\circ} \mathrm{C}$ for 60 minutes followed by anti-chlor with $5 \mathrm{~g} / \mathrm{l}$ sodium bi-sulphite at $60^{\circ} \mathrm{C}$ for 15 minutes. Subsequently the fabric was rinsed with cold water and left for drying at ambient conditions. The process file is shown in Figure 1.

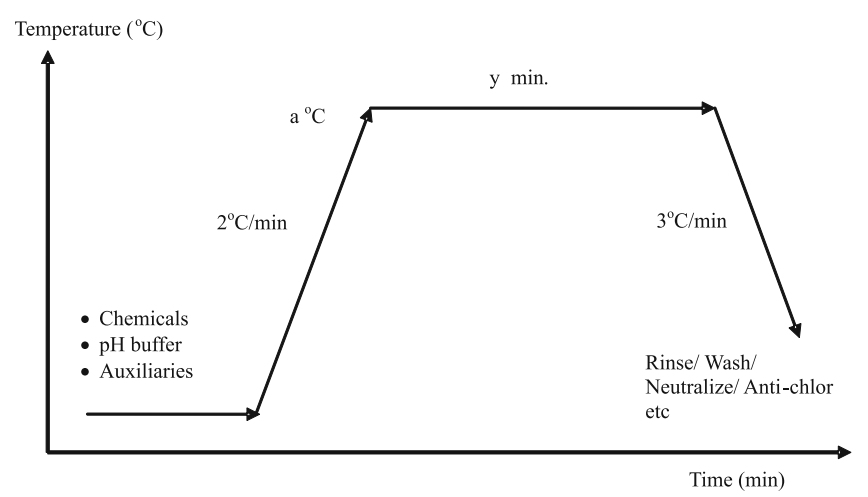

Figure 1. Pretreatment process profile

\section{Measurement of weight loss (\%)}

PLA fabric was conditioned at standard conditions of $25^{\circ} \mathrm{C}$ and $65 \%$ R.H before testing. The following formula was used to calculate the weight loss of samples after processing, where $\mathrm{W}_{1}$ and $\mathrm{W}_{2}$ were weights of the samples before and after processing dried at ambient conditions: Weight loss $\%=\left[\mathrm{W}_{1}-\mathrm{W}_{2}\right] \cdot 100 / \mathrm{W}_{1}$

\section{Tensile measurement}

Yarns were taken out from control and each of the treated fabric samples and conditioned at standards conditions of $25^{\circ} \mathrm{C}$ and $65 \%$ R.H before testing. Tests were performed according to BS EN ISO 2062:1995, using Instron Model 1122 tensile tester with a gauge length of $100 \mathrm{~mm}$ and at a strain rate of $1 \mathrm{~min}^{-1}$. Ten tests were performed on each of the yarn samples and the results acquired through desktop computer interfaced to the testing machine. The raw data was received and analyzed through computer software QT.

\section{Sem analysis}

The surface morphology of PLA fibers was investigated using Scanning Electron Microscope. Fabric samples were sputter-coated with Gold in Polaron coating unit (model 
E5100). The samples attached on sample holder were loaded into the Hitachi SEM (model S-3000N). Gun-to-samples distance was $8-9 \mathrm{~mm}$ and voltage of $5 \mathrm{kV}$ was applied to accelerate electron toward the sample under high vacuum conditions. Electron beam focusing, image magnification and brightness/ contrast were adjusted to take the photo micrographs through SmatSEM software (Hitachi).

\section{RESULTS AND DISCUSSION}

\section{Effect of scouring on weight loss (\%)}

Figure 2 showed the effect of sodium carbonate concentration and processing temperature on the weight loss of PLA during scouring. The results showed that at constant concentration of sodium carbonate; higher the temperature, higher was the weight loss. According to the results PLA could be treated up to $100^{\circ} \mathrm{C}$ without appreciable weight loss. The $\mathrm{pH}$ measurement at the end of scouring revealed that $\mathrm{pH}$ of the scouring bath at $60^{\circ} \mathrm{C}$ changed a little, however, for temperature above $60^{\circ} \mathrm{C}$ the $\mathrm{pH}$ decreased appreciably so that the final bath- $\mathrm{pH}$ was lower. The results indicated that as the temperature increased, so was the degradation of PLA fibers increased. At high temperature hydrolysis of PLA was high which led to the formation of more carboxylic acid groups at the end of polymer chains. These carboxylic acid groups were neutralized with alkali present in the bath resulting in decrease of $\mathrm{pH}$ of the scouring bath, Scheme 1. The decrease in weight of fiber during scouring meant that polymer chains were split into smaller fragments. These low molecular weight polymer chains were easily washed off resulting in lowering of yarn weight.

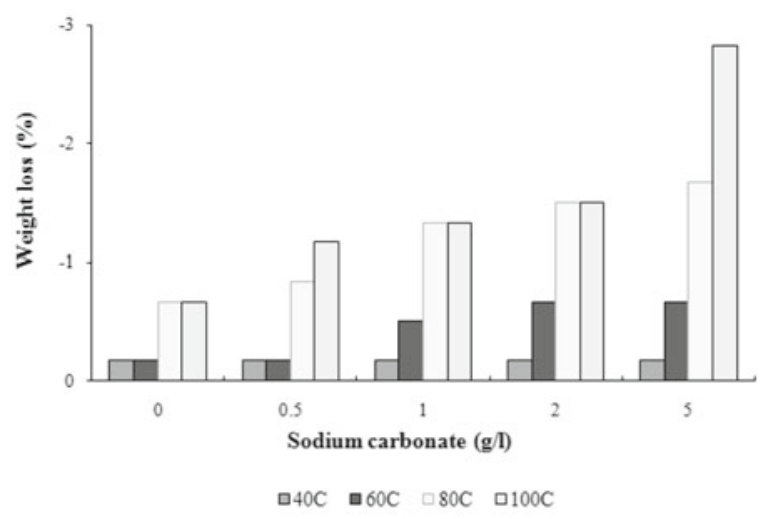

Figure 2. Weight loss of PLA during scouring

\section{Effect of bleaching on weight loss (\%)}

Figure 3 presented the weight loss of scoured PLA treated with various oxidative bleaching agents. It was observed that hydrogen peroxide caused more damage than any of the other bleaching agents. Hydrogen peroxide was applied by the exhaust and CPB techniques. The exhaust method caused more damage than CPB due to the bleaching being carried out at higher temperature in the former technique. Bleaching with sodium hypochlorite or sodium chlorite caused a little change in weight loss of the PLA fabric. It was concluded from the results that long liquor high temperature oxidative conditions were more damaging to PLA than low temperature ones.

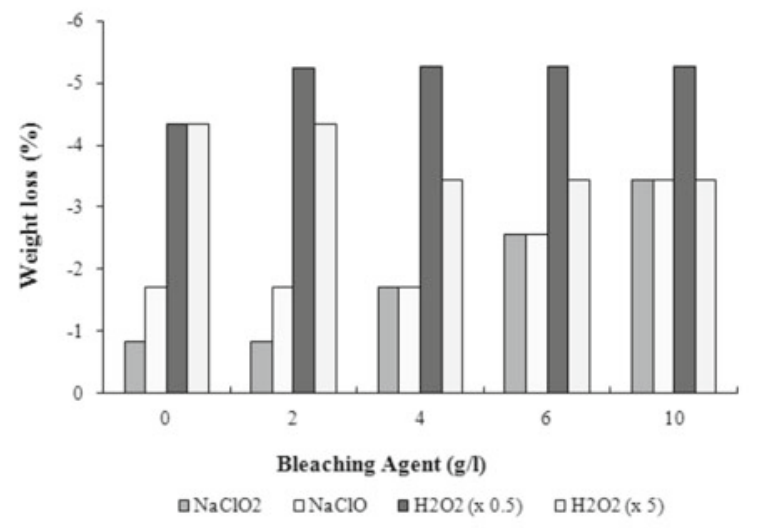

Figure 3. Weight loss of PLA during bleaching

\section{Effect of scouring on tensile properties}

The tensile properties of yarns taken from scoured PLA knitted fabric were measured and presented in Table 1. The scoured PLA fabric was treated at various alkali concentrations $(0.0,0.5$ and $5.0 \mathrm{~g} / \mathrm{l})$ and temperatures $\left(40^{\circ} \mathrm{C}, 60^{\circ} \mathrm{C}, 80^{\circ} \mathrm{C}\right.$ and $\left.100^{\circ} \mathrm{C}\right)$. The results showed that up to $60^{\circ} \mathrm{C}$, increasing alkali concentration had little effect on tensile properties. In the rage of $80^{\circ} \mathrm{C}-100^{\circ} \mathrm{C}$, increase in alkali concentration caused ever higher loss in tensile properties. The glass transitions temperature of PLA lie around $60^{\circ} \mathrm{C}$. At $\mathrm{T}_{\mathrm{g}}$ the structure of polymer became more accessible due o the formation of temporary voids, the later being formed due to the vibration of polymer chains. The higher accessibility to hot-alkaline scouring liquor above $\mathrm{T}_{\mathrm{g}}$ resulted in accelerated hydrolysis of PLA polymer. The hydrolysis resulted in the breakdown of polymer chains into small fragments of low number average molecular weight $\left(\mathrm{M}_{\mathrm{n}}\right)$ and hence a decrease in strength of the fiber. It was suggested that scouring could be carried out safely without appreciable loss in weight and tensile properties at $60^{\circ} \mathrm{C}$ even at 5 $\mathrm{g} / \mathrm{l}$ sodium carbonate. On industrial scale, scouring of<smiles>CC(O)C(=O)OC(C)C(=O)OC(C)C(=O)O</smiles><smiles>CC(O)C(=O)OC(C)C(=O)OC(=O)C(=O)O</smiles><smiles>CC(O)C(=O)OC(C)C(=O)O</smiles><smiles>CC(O)C(=O)OC(C)C(=O)O[NH3+]</smiles>

Scheme 1. Schematic hydrolysis of PLA polymer 
synthetic fibers is chemically a mild process. However blends of synthetic and natural fibers require more severe conditions. Since scouring of cotton is carried out nearly at the boil, PLA may be damaged as evident from the data presented in Table 1. The scouring of PLA-cotton blends might be carried out at lower temperature, though it will take long processing time. It might also be deduced from the data that tenacity was a more sensitive measurement of damage to PLA yarn than weight loss e.g. at $60^{\circ} \mathrm{C}$ weight loss measurements did not give any idea of damage but there was still a decrease in tenacity even at the same weight loss. Figure 4 showed the correlation between weight loss and tenacity of PLA yarn. It was evident from the coefficient of determination i.e. $\mathrm{R}^{2}$ value $(0.92)$ that there was strong correlation

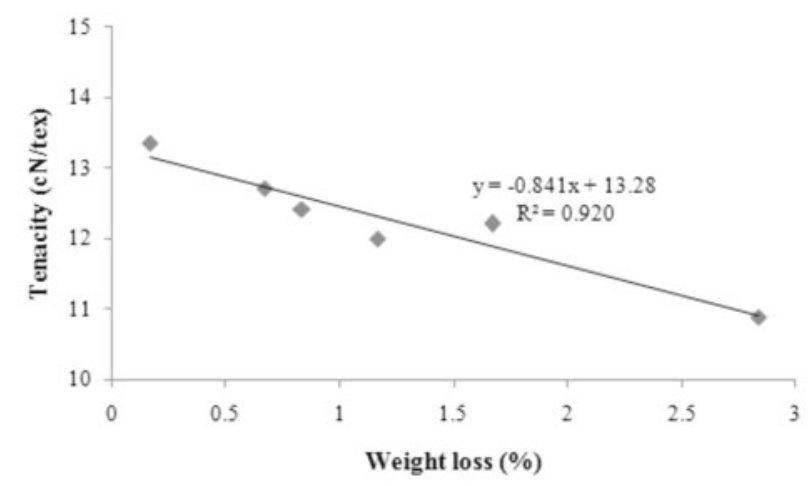

Figure 4. Correlation between weight loss and tenacity of PLA yarns between weight loss and tenacity. The negative value of slope meant that change in tenacity with respect to weight loss was at a rate of 0.84 units.

\section{Effect of bleachig agents on tensile properties}

Table 2 presented the tensile properties of PLA yarns taken from knitted fabric bleached with various bleaching agents. The results showed that hydrogen peroxide, in the exhaust process, caused the greatest damage than any other bleach system. The tenacity of yarns decreased from $13.5 \mathrm{cN} /$ tex to $8.4 \mathrm{cN} /$ tex. It was evident from the data that control for hydrogen peroxide had even less tenacity than treated samples. This showed that alkalinity contributed a lot to the deterioration of the fibers. Indeed hydrogen peroxide is a weak acid, therefore alkali was consumed in its presence and this resulted in better retention of yarn strength, Scheme 2. However, if ratio of hydrogen peroxide to sodium hydroxide is maintained constant, there would be severe damage to the yarns. The strain percentage and hence deformation of the yarns decreased significantly particularly at high alkali concentration that made yarns less stretchable. $\mathrm{H}_{2} \mathrm{O}_{2}+\mathrm{NaOH} \longrightarrow \mathrm{HOO}^{-}+\mathrm{Na}^{+}$

Scheme 2. Schematic reaction of hydrogen peroxide with sodium hydroxide

In the case of other bleaches such as sodium hypochlorite, sodium chlorite and hydrogen peroxide (CPB) systems there was negligible loss in strength. The results suggested that PLA might be bleached with hydrogen

Table 1. Tensile properties of PLA scoured with sodium carbonate at process conditions

\begin{tabular}{|c|c|c|c|c|c|}
\hline $\begin{array}{l}\mathrm{Na}_{2} \mathrm{CO}_{3} \\
{[\mathrm{~g} / \mathrm{l}]}\end{array}$ & $\begin{array}{c}\text { Temperature } \\
{\left[{ }^{\circ} \mathrm{C}\right]}\end{array}$ & Tenacity [cN/tex] & $\begin{array}{c}\text { Strain } \\
{[\%]}\end{array}$ & Modulus [N/tex] & $\begin{array}{c}\text { Energy to Break } \\
{[\mathrm{N} / \mathrm{tex}]}\end{array}$ \\
\hline- & - & 14.6 & 61.5 & 0.83 & 0.17 \\
\hline 00 & \multirow{3}{*}{40} & 13.6 & 64.8 & 0.95 & 0.17 \\
\hline 0.5 & & 13.6 & 62.1 & 0.90 & 0.17 \\
\hline 5.0 & & 13.8 & 62.0 & 0.97 & 0.17 \\
\hline 00 & \multirow{3}{*}{60} & 13.1 & 64.1 & 0.85 & 0.17 \\
\hline 0.5 & & 12.6 & 60.0 & 0.78 & 0.15 \\
\hline 5.0 & & 12.8 & 60.0 & 0.74 & 0.15 \\
\hline 00 & \multirow{3}{*}{80} & 13.1 & 62.0 & 0.82 & 0.17 \\
\hline 0.5 & & 12.4 & 61.0 & 0.74 & 0.15 \\
\hline 5.0 & & 12.2 & 60.9 & 0.79 & 0.15 \\
\hline 00 & \multirow{3}{*}{100} & 11.2 & 63.2 & 0.82 & 0.15 \\
\hline 0.5 & & 11.2 & 62.0 & 0.76 & 0.15 \\
\hline 5.0 & & 10.8 & 60.0 & 0.86 & 0.14 \\
\hline
\end{tabular}

(Time 20 minutes, LMR of 10:1)

Table 2. Tensile properties of PLA bleached with various bleaching agents

\begin{tabular}{|c|c|c|c|c|c|c|}
\hline \multicolumn{2}{|c|}{ Bleaching agent } & Concentration & Tenacity [cN/tex] & $\begin{array}{c}\text { Strain } \\
{[\%]}\end{array}$ & Modulus [N/tex] & Energy to Break [N/tex] \\
\hline \multicolumn{2}{|c|}{ Greige } & & 14.6 & 61.5 & 0.83 & 0.18 \\
\hline \multicolumn{2}{|c|}{ Scoured } & - & 13.5 & 65.1 & 0.66 & 0.17 \\
\hline \multirow{3}{*}{\multicolumn{2}{|c|}{$\mathrm{NaClO}_{2}$}} & $0 \%$ o wf & 13.2 & 63.4 & 0.61 & 0.16 \\
\hline & & 2 & 12.8 & 64.3 & 0.61 & 0.16 \\
\hline & & 10 & 12.4 & 64.9 & 0.62 & 0.17 \\
\hline \multirow{6}{*}{$\mathrm{H}_{2} \mathrm{O}_{2}$} & \multirow{3}{*}{$\begin{array}{l}\mathrm{NaOH} \\
0.5 \mathrm{~g} / \mathrm{l}\end{array}$} & $0 \mathrm{ml} / \mathrm{l}$ & 11.1 & 65.3 & 0.60 & 0.17 \\
\hline & & 1 & 11.3 & 69.9 & 0.53 & 0.17 \\
\hline & & 5 & 12.9 & 70.9 & 0.55 & 0.18 \\
\hline & \multirow{3}{*}{$\mathrm{NaOH} 3.0 \mathrm{~g} / \mathrm{l}$} & $0 \mathrm{ml} / \mathrm{l}$ & 6.2 & 20.1 & 0.77 & 0.02 \\
\hline & & 1 & 8.4 & 33.0 & 0.77 & 0.06 \\
\hline & & 5 & 11.9 & 59.6 & 0.64 & 0.15 \\
\hline \multirow{3}{*}{\multicolumn{2}{|c|}{$\mathrm{NaClO}$}} & $0 \mathrm{~g} / \mathrm{l} \mathrm{Cl} 2$ & 14.3 & 63.0 & 0.73 & 0.17 \\
\hline & & 2 & 13.9 & 60.1 & 0.78 & 0.15 \\
\hline & & 10 & 13.8 & 62.9 & 0.84 & 0.18 \\
\hline \multirow{3}{*}{\multicolumn{2}{|c|}{$\begin{array}{l}\mathrm{H}_{2} \mathrm{O}_{2} \\
\text { (CPB) }\end{array}$}} & $0 \mathrm{ml} / \mathrm{l}$ & 13.4 & 61.6 & 0.83 & 0.17 \\
\hline & & 10 & 13.2 & 65.4 & 0.80 & 0.18 \\
\hline & & 50 & 13.2 & 65.2 & 0.72 & 0.18 \\
\hline
\end{tabular}



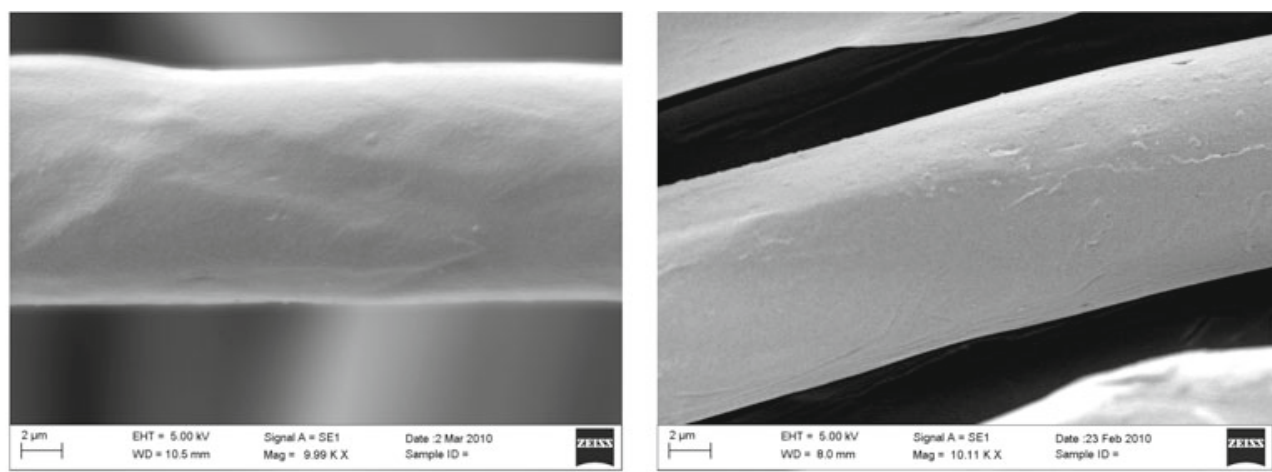

a: Greige fabric

d: $\mathrm{NaClO}_{2}$ bleached PLA
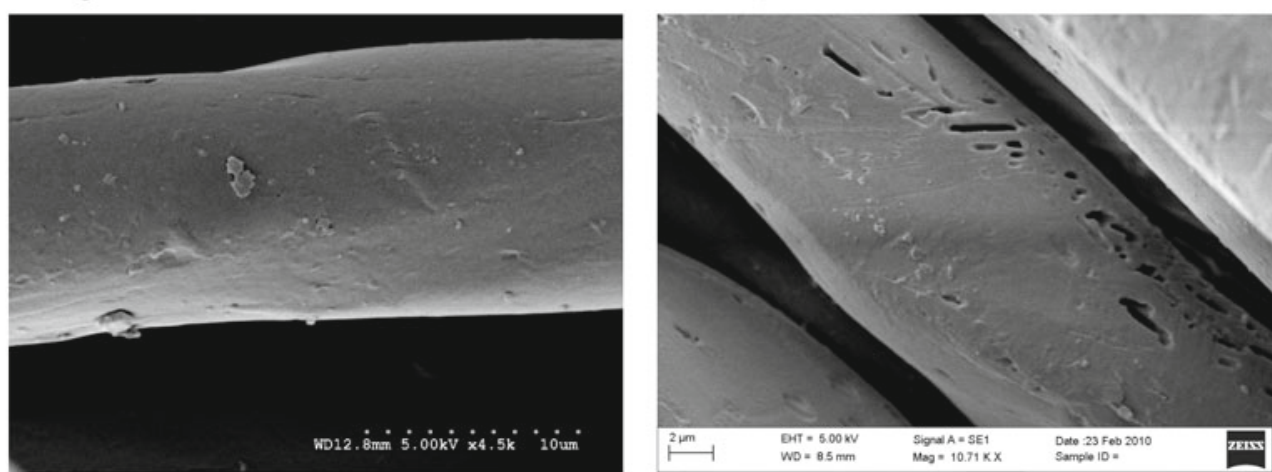

b: $\mathrm{Na}_{2} \mathrm{CO}_{3} 5 \mathrm{~g} / 1,60^{\circ} \mathrm{C}$

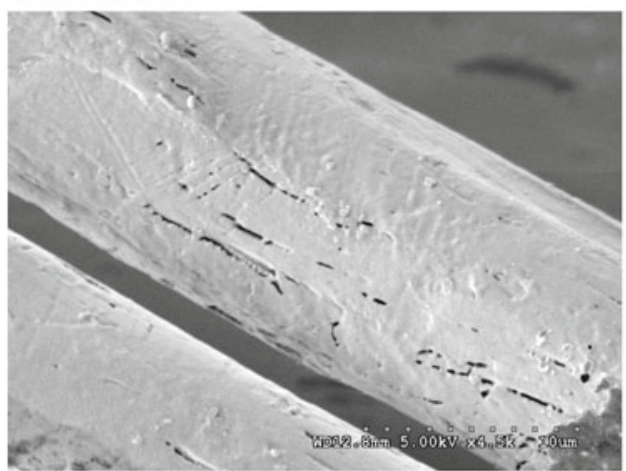

e: $\mathrm{H}_{2} \mathrm{O}_{2}$ bleached PLA

c: $\mathrm{Na}_{2} \mathrm{CO}_{3} 5 \mathrm{~g} / \mathrm{l}, 100^{\circ} \mathrm{C}$

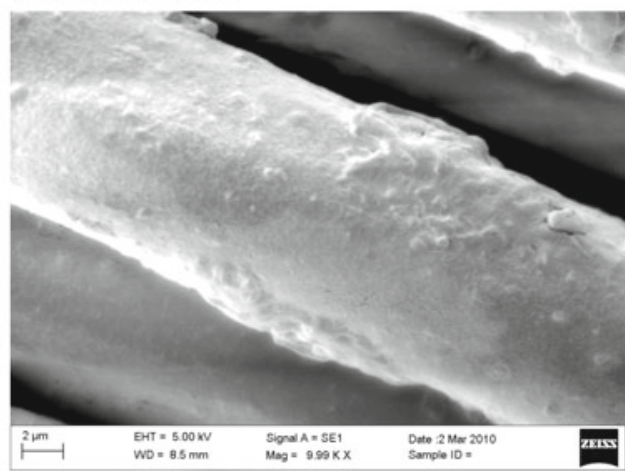

f: $\mathrm{H}_{2} \mathrm{O}_{2}(\mathrm{CPB})$ bleached PLA

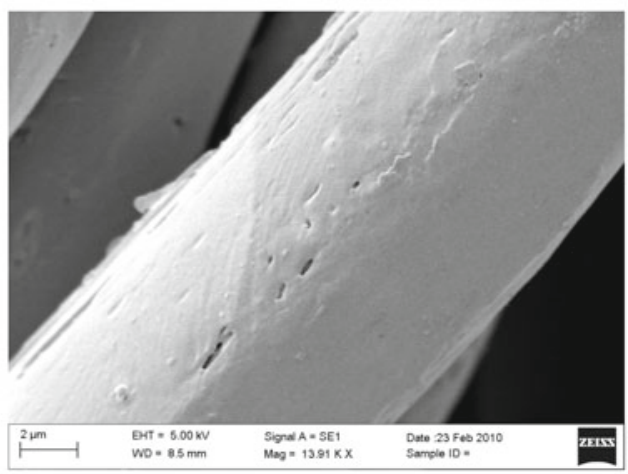

g: $\mathrm{NaClO}$ bleached PLA

Figure 5. SEM photo micrographs of PLA fibers

peroxide at low concentration however; if high whiteness was required sodium chlorite was a better choice. Sodium chlorite was applied at process conditions usually adopted in industry for the bleaching of cotton i.e. at $85^{\circ} \mathrm{C}$ and $\mathrm{pH}$ 4.5. The data showed that PLA yarns retained strength at high temperature when processed in the acidic $\mathrm{pH}$. Since PLA could bear severe process conditions of cotton bleaching, it was suggested that blends of PLA with cotton could be bleached safely with sodium chlorite. Similarly PLA might be bleached with sodium hypochlorite without appreciable loss in tensile properties. Little damage to PLA might be attributed to low temperature oxidative conditions of sodium hypochlorite bleaching. Sodium hypochlorite is still widely used in the textile industry to bleach cotton fabrics, particularly in the denim washing, despites the environmental issues. Negligible damage to PLA implied that PLA-cotton blends could be treated with sodium hypochlorite on industrial scale safely. Since chlorine bleaches are notorious for polluting environment, hydrogen peroxide might be applied by the $\mathrm{CPB}$ technique as low temperature oxidative conditions did not damage PLA yarns. 


\section{Sem Analysis}

The surface morphology of PLA fibers subjected to various pretreatment process conditions was investigated using scanning electron microscope, Figure 5. The photo micrographs $a$ and $b$ showed the greige PLA and PLA scoured at $60^{\circ} \mathrm{C}$, respectively. There was little change in surface topography of fibers. The photo micrograph c showed PLA scoured at $100^{\circ} \mathrm{C}$. There were clear differences in surface morphology treated at $60^{\circ} \mathrm{C}$ and at $100^{\circ} \mathrm{C}$. This explained why strength of PLA decreased at high temperature. The photo micrographs d to g showed the effect of various bleaching agents on the surface morphology of PLA fibers. The photo micrograph d showed that PLA fibers were little damaged in acidic sodium chlorite solutions. The photo micrographs e and f showed PLA treated with hydrogen peroxide. Photo micrograph e showed that hydrogen peroxide, when applied by the exhaust technique, caused excessive hole-formation in the fibrous structure. The excessive formation of holes led to significant strength loss in tensile properties of PLA yarn. It was evident from photo micrograph $f$ that hydrogen peroxide, when applied by CPB technique caused a little damage to PLA fibers and that these damaging effects were restricted to surface only. Due to the presence of high amount of alkali in the bleach bath, surface of PLA fibers was eroded irregularly. The photo micrograph g showed some tiny holes in the fibers, however, these holes were not penetrated deep into the fibrous structure. This hypothesis was supported by the tensile measurement which showed little change in tenacity when PLA was treated with sodium hypochlorite.

\section{CONCLUSION}

PLA knitted fabric was subjected to scouring and bleaching at various process conditions. The alkaline scouring of PLA above $60^{\circ} \mathrm{C}$ in the presence of detergent exhibited adverse effect on tensile properties. The $\mathrm{pH}$ measurements at the end of processing showed that high temperature processing caused $\mathrm{pH}$ drop which was attributed to hydrolysis of PLA polymer. The bleaching of PLA with sodium hypochlorite and sodium chlorite did not appreciably affect the weight loss and tensile properties. The bleaching with hydrogen peroxide by the CPB technique didn't damage PLA appreciably; however, when applied by the exhaust technique it rendered irreparable damage to the fibers. If hydrogen peroxide was the only option, CPB bleaching could be carried out to avoid strength loss of the fabric. In the case of polyester-cotton blends, bleaching with sodium chlorite or sodium hypochlorite might be carried out to effectively bleach the blend with little damage to the PLA portion.

\section{LITERATURE CITED}

1. Stevens, E.S. What makes green plastics green? BioCycle. March 2003, 24-27.

2. Ho, K.L.G., Pometto, A.L., Gadea-Rivas, A., Briceno, J.A. \& Rojas, A. (1999). Degradation of polylactic acid (PLA) plastic in Costa Rican soil and low state University compost rows, J. Environ. Polym. Degradation 7(4), 173-177. DOI:10.1023/A:1022874530586.

3. Blackburn, R.S. (2005). Biodegradable and Sustainable Fibres, Cambridge, UK: Woodhead Publishing Limited.
4. www.natureworksllc.com/About-NatureWorks-LLC

5. Dugan, J.S. (2000). Novel Properties of PLA Fibre, Research Fiber Innovation Technology, Inc. Retrieved February 05, 2014, from www.fitfibers.com/files/PLA20\%Fibers.doc

6. Yang, Y. \& Huda, S. (2003). Comparison of disperse dye exhaustion, color yield, and colorfastness between polylactides and poly (ethylene terephthalate), J. Appl. Polym. Sci. 90 (12), 3285-3290. DOI: 10.1002/app.13062.

7. Hawkyard, C. (2004). Synthetic Fibre Dyeing. Bradford, UK: SDC.

8. Madaras, G.W., Parish, G.J. \& Shore, J. (1993). Batchwise Dyeing of Woven Cellulosic Fabrics, Bradford, UK: SDC.

9. Sadov, F., Korchagin, M. \& Matetsky, A. (1973). Chemical Technology of Fibrous Materials, USSR: MIR.

10. Tomasino, C. (1992). Chemistry \& Technology of Fabric Preparation and Finishing, NCSU, USA: NCSU.

11. Broadbent, A.D. (2011). Basic Principles of Textile Coloration, Bradford, UK: SDC.

12. Karmakar, A.R. (1999). Chemical Technology in the Pretreatment Processes of Textiles, Amsterdam, Netherlands: Elsevier Science B.V.

13. Carr, C.M. (1995). Chemistry of the Textiles Industry, Glasgow, UK: Blackie Academic \& Professional.

14. Joziasse, C.A.P., Grijpma, D.W., Bergsma, J.E., Cordewener, F.W., Bos, R.R.M. \& Pennings, A.J. (1998). The influence of morphology the (hydrolytic degradation of as polymerized and hot-drawn poly (L-lactide)), Coll. Polym. Sci. 276(11), 968-975. DOI: 10.1007/s003960050335.

15. Grizzi, I., Garreau, H., Li, S. \& Vert, M. (1995). Hydrolytic degradation of devices based on poly (DL-lactic acid) size-dependence, Biomaterials 16(4), 305-311. DOI: 10.1016/0142-9612(95)93258-F.

16. Nakamura, T., Hitomi, T.S., Watanabe, S., Shimizu, Y., Jamshidi, K., Hyon, S.H. \& Ikada, Y. (1989). Bioabsorption of polylactides with different molecular properties, J. Biomed. Mater. Res. 23(10), 1115-1130. DOI: 10.1002/jbm.820231003.

17. Baig, G.A. (2013). Reduction clearing of simulated disperse dyed PLA fabrics and their tensile properties, Indian J. Fiber Tex. Res. 38(1), 22-28.

18. Baig, G.A. (2013). Hydrolytic stability of PLA during textile wet processing, Fibres Polym. 14(11), 1912-1918. DOI: 10.1007/s12221-013-1912-7.

19. Baig, G.A. \& Carr, C.M. (2013). Pretreatment of polylactic acid (PLA) fabrics. In $6^{\text {th }}$ International TexTeh, 17-18 October, 2013 (pp. 165-180), Bucharest, Romania.

20. Ahmad, G. (2012). Hydrolytic stability of PLA during Textile Wet Processing. Doctoral dissertation, University of Manchester, Manchester, UK.

21. Suesat, J., Sae-be, P. \& Suwanrui, P. (2012). Effect of pretreatment and dyeing processes on the physical properties of Poly (Lactic acid)/Cotton blended fabric, Adv. Mater. Res. 486, 253-259. 